\title{
APONTAMENTOS SOBRE A REVOLUÇÃO BURGUESA NO BRASIL NA OBRA DE FLORESTAN FERNANDES
}

Márcia Pereira da Silva Cassin ${ }^{1}$

\section{Resumo}

0 artigo desenvolve uma síntese sobre os principais aspectos acerca do tema da revolução burguesa no Brasil presentes na obra de Florestan Fernandes. A primeira parte versa sobre a formação do Estado nacional a partir da independência, buscando identificar as raízes da dominação burguesa no Brasil e de sua natureza autocrática. A segunda parte se debruça sobre o desenvolvimento do capitalismo dependente, em suas diferentes fases, e o processo de consolidação da revolução burguesa no Brasil.

Palavras-chave: Revolução burguesa no Brasil; Capitalismo dependente; Autocracia burguesa.

\begin{abstract}
The article develops a synthesis about the main aspects about the theme of the bourgeois revolution in Brazil present in the work of Florestan Fernandes. The first part deals with the formation of the national state from independence, seeking to identify the roots of bourgeois domination in Brazil and its autocratic nature. The second part deals with the development of dependent capitalism, in its different phases, and the consolidation process of the bourgeois revolution in Brazil.
\end{abstract}

Keywords: bourgeois revolution in Brazil; Dependent capitalism; Bourgeois autocracy.

\section{Introdução}

Neste ano em que se comemora o centenário de Florestan Fernandes, quatro décadas nos separam da publicação daquela que pode ser

\footnotetext{
${ }^{1}$ Mestre e doutoranda em Serviço Social pela UFRJ. Docente na Faculdade de Serviço Social da UERJ. E-mail: marcia.cassin@hotmail.com.
} 
considerada sua obra magistral: A revolução burguesa no Brasil. Como é comum a todo clássico, as formulações impressas neste livro não sucumbiram à força implacável do tempo, mas são capazes de traduzir, com renovada atualidade, os dilemas de nossos dias.

A compreensão do debate acerca do caráter da revolução burguesa no Brasil é imprescindível ao exercício de interpretação da realidade contemporânea do país. Tal entendimento requer uma cautelosa análise sobre os processos que conduziram ao amadurecimento do tipo particular de capitalismo que se desenvolveu no Brasil, bem como sobre a formação do Estado e sua relação com as classes sociais. Não é outro o sentido que Florestan imprime à investigação empreendida nesta obra, cuja redação se inicia em 1966 e se completa em 1974 após um intervalo de seis anos motivado, entre outras razões, por sua aposentadoria compulsória da USP no período dos "anos de chumbo".

0 presente artigo busca desenvolver uma breve síntese sobre os aspectos de maior relevo contidos na obra supracitada. A primeira parte versa sobre a formação do Estado nacional a partir da independência, buscando identificar as raízes da dominação burguesa no Brasil e de sua natureza autocrática. A segunda parte se debruça sobre o desenvolvimento do capitalismo dependente, em suas diferentes fases, e o processo de consolidação da revolução burguesa no Brasil. Longe da perspectiva de esgotar o debate - tarefa, aliás, impraticável diante do imenso arsenal teórico e conceitual mobilizado por Florestan nesta obra o que se propõe ao longo deste texto é um resgate das principais contribuições do autor acerca do tema da revolução burguesa no Brasil, com o intuito de somarmo-nos aos esforços coletivos de preservação e estudo de seu valoroso legado.

\section{As particularidades da formação do Estado e a dominação burguesa no Brasil}

A análise da revolução burguesa, para Florestan Fernandes, constitui um tema crucial no estudo sociológico da formação e desenvolvimento do 
capitalismo no Brasil. Por isso, o autor propõe como objetivo central de sua obra A revolução burguesa no Brasil examinar a etapa de consolidação do modo de produção capitalista no Brasil "como uma realidade parcialmente autônoma, com tendências bem definidas à vigência universal e à integração nacional" (FERNANDES, 2005, p. 29).

Florestan inicia sua reflexão com uma indagação sobre a legitimidade do uso do termo "burguesia" na sociedade brasileira. Segundo o autor, não se pode associar o senhor de engenho ao burguês, nem a aristocracia agrária à burguesia, pois estes ocupavam uma posição marginal na mercantilização da produção e o que realizavam como excedente não poderia ser considerado como um lucro propriamente dito; ou seja, não estabeleciam relações burguesas de produção. Por outras palavras: "No conjunto, nada justificaria assimilar o senhor de engenho ao 'burguês', e é um contrassenso pretender que a história da burguesia emerge com a colonização" (Idem, p. 33).

Conforme Florestan, tratava-se antes de uma congérie social que duma classe propriamente dita. Ou seja, um conjunto de setores das elites agrárias e oligárquicas que iriam absorver um padrão de civilização burguês, assumindo os papéis da burguesia clássica:

O 'burguês', que nascera sob o signo de uma especialização econômica relativamente diferenciada, iria representar, portanto, papéis históricos que derivavam ou se impunham como decorrência de suas funções econômicas na sociedade nacional. Ele nunca seria, no cenário do Império, uma figura dominante ou pura, com força socialmente organizada, consciente e autônoma (FERNANDES, 2005, p. 36).

0 autor questiona, na sequência, se existiu ou não uma revolução burguesa no Brasil e como teria sido possível o país se tornar capitalista sem a universalização do trabalho assalariado e a expansão da ordem social competitiva. Nesse sentido, falar em revolução burguesa consiste em "procurar os agentes humanos das grandes transformações históricas que estão por trás da desagregação do regime escravocrata-senhorial e da formação de uma sociedade de classes no Brasil" (Idem, p. 37).

Logo, os termos burguesia e revolução burguesa se colocam no horizonte da análise, segundo o autor, não como uma tentativa de explicar o 
presente do Brasil através do passado dos povos europeus, mas como um caminho para se pensar de que forma o Brasil teria conseguido atingir a modernidade capitalista.

Os móveis capitalistas foram introduzidos no país juntamente com a colonização, mas só criaram condições de se desenvolverem com a crise da sociedade colonial e a criação de um Estado nacional, por meio da Independência. Com a Independência, "o poder deixará de se manifestar como imposição de fora para dentro, para organizar-se a partir de dentro" (p. 50). Conforme o autor, a Independência constituiu a primeira grande revolução social que se operou no Brasil. No entanto, não contou com a participação de manifestações populares. Seu caráter revolucionário se expressa pela ruptura política com o estatuto colonial, mas a ordem social e os aparatos de poder das elites nativas foram conservados. Ou seja, tratavase de um processo de ruptura altamente domesticado, seguro e controlado.

A independência pressupunha, assim, um elemento revolucionário, voltado para despojar a ordem social da dependência em relação à metrópole, e outro conservador, com o propósito de preservar e fortalecer o substrato material, social e moral do estatuto colonial.

A grande lavoura e a mineração, nas condições em que podiam ser exploradas produtivamente, impunham a perpetuação das estruturas do mundo colonial - da escravidão à extrema concentração de renda e ao monopólio do poder por reduzidas elites, com a marginalização permanente da enorme massa de homens livres que não conseguia classificar-se na sociedade civil e a erosão invisível da soberania nacional nas relações econômicas, diplomáticas ou políticas com as grandes potências (FERNANDES, 2005, p. 51).

O elemento revolucionário se tornará o "fermento histórico" que possibilitará a formação de uma sociedade nacional. Para Fernandes, a absorção do liberalismo pelas elites nativas ${ }^{2}$ impulsionará a luta contra os entraves postos pelo estatuto colonial aos seus interesses. Dessa forma,

\footnotetext{
2 Cabe esclarecer que o uso recorrente do termo "elite" ou "elites nativas" no presente artigo é uma referência aos termos usados pelo autor. Convém lembrar que nesta obra, Florestan Fernandes, mesmo que já não com o mesmo teor verificado em seus trabalhos anteriores, ainda mesclava ao arsenal teórico marxista muitos elementos de cariz weberiano, o que fica um tanto claro no seu uso de categorias como "estamento", "ordem social competitiva" e, claro, "elite".
} 
$\mathrm{Na}$ fase de transição, as elites encaravam o Estado, naturalmente, como 'meio' e 'fim': 'meio', para realizar a internalização dos centros de decisão política e promover a nativização dos círculos dominantes; e o 'fim' de ambos os processos, na medida em que ele consubstanciava a institucionalização do predomínio político daquelas elites e dos 'interesses internos' com que elas se identificavam (FERNANDES, 2005, p. 53).

Vê-se, portanto, que a criação de um Estado independente constituiu uma necessidade para o rompimento com o bloqueio à autonomia política das elites nativas, bem como para o fortalecimento de seu poder de dominação estamental. O liberalismo foi absorvido somente nos aspectos que convinham ao jogo político das elites, principalmente naqueles concernentes à modernização do Estado. Ao passo que foi ignorado no que dizia respeito aos seus componentes utópicos expressos em sua filosofia política e no seu sistema de valores. Dito de outra forma: "O que ocorreu com o Estado nacional independente é que ele era liberal somente em seus fundamentos formais. Na prática, ele era instrumento da dominação patrimonialista no nível político" (p. 90).

Partindo da análise empreendida, o autor sugere a existência de duas linhas de desenvolvimento do capitalismo no Brasil. A primeira se origina com a própria colonização e se prende aos desígnios econômicos do capitalismo comercial. A segunda teria surgido da "autonomização política e das tendências históricas que ela engendrou, de criação de uma economia, de um Estado e de uma sociedade nacionais, sob modelos institucionais tomados da civilização ocidental moderna" (p. 105).

Tal processo, para Fernandes, consiste em uma evolução histórica na qual o "setor velho" da economia não se transformou nem se destruiu para gerar o "setor novo" (p. 104). A formação de um Estado e de uma sociedade nacionais implicou uma adaptação do país aos modelos institucionais das civilizações modernas, criando as condições para a absorção de um "espírito burguês".

O paradoxo está no fato de que a "revolução nacional" não resultou de uma "revolução econômica", por isso não rompeu com a dependência em relação ao mercado externo, mas manteve as bases de uma economia totalmente voltada para a exportação, que produzia para fora e consumia de 
fora: "um mercado interno nuclearmente heteronômico e voltado para fora" (p. 111).

Conforme o autor, a formação e o desenvolvimento do capitalismo moderno foram conduzidos por duas categorias sociais específicas, que tiveram um papel ativo na ruptura com o passado e na criação das novas estruturas econômicas, agindo como os verdadeiros protagonistas da revolução burguesa no Brasil: os fazendeiros de café e os imigrantes. 0 fazendeiro de café, interessado na continuidade da política permanente de defesa do café e na manutenção de sua fonte de riqueza e lucro, converteuse em um agente do capitalismo comercial e financeiro, consolidando uma posição republicana e absorvendo o trabalho livre. Já o imigrante, "encarnaria de modo mais completo a concretização interna da mentalidade capitalista e iria desempenhar os principais papeis econômicos que estruturaram e dinamizaram a evolução do capitalismo no Brasil" (p. 168).

Esses setores de classe "aburguesados" estabelecerão uma aliança com as oligarquias e com o Estado na implantação da revolução burguesa, com o objetivo em comum de "amortecer a mudança social espontânea" (p. 241), garantindo a manutenção da ordem.

As próprias 'associações de classe', acima dos interesses imediatos das categorias econômicas envolvidas, visavam a exercer pressão e influência sobre o Estado e, de modo mais concreto, orientar e controlar a aplicação do poder político estatal, de acordo com seus fins particulares. Em consequência, a oligarquia não perdeu a base de poder que lograra antes, como e enquanto aristocracia agrária; e encontrou condições ideais para enfrentar a transição, modernizando-se, onde isso fosse inevitável e irradiando-se pelo desdobramento das oportunidades novas, onde isso fosse possível (p. 240).

Fernandes observa que nas sociedades dependentes de extração colonial, como é o caso do Brasil, o capitalismo é introduzido antes da constituição da ordem social competitiva e se defronta com estruturas econômicas, sociais e políticas elaboradas sob o regime colonial, apenas parcial e superficialmente ajustadas aos padrões capitalistas da vida econômica. Tais estruturas "não só moldaram a sociedade nacional subsequente: determinaram, a curto e a largo prazos, as proporções e o 
alcance dos dinamismos econômicos absorvidos do mercado mundial" (p. 180).

Essas estruturas herdadas da colônia se revelaram bem flexíveis em relação à reorganização do mercado colonial e aos negócios de exportação e importação, contudo foram pouco elásticas no que concerne à absorção dos dinamismos econômicos centrais para a expansão interna do capitalismo. Conforme o autor, "a ordem social escravocrata e senhorial não se abriu facilmente aos requisitos econômicos, sociais, culturais e jurídico-políticos do capitalismo" (p. 181). 0 desenvolvimento lento e gradual do capitalismo se explica, em parte, pelo caráter de modernização conservadora da independência, posto que:

Se a revolução política, desencadeada pela emancipação nacional, fosse também uma revolução econômica e social, as coisas teriam se passado de outro modo. Então, a ordem social competitiva teria nascido juntamente com o Estado nacional independente e com o surto de modernização, provocado pela incorporação direta da economia brasileira ao mercado mundial (FERNANDES, 2005, p. 183).

A emergência e expansão do capitalismo como uma realidade histórica aliada à presença da ordem social escravocrata e senhorial gerou uma acomodação de formas econômicas opostas e exclusivas, resultando no desenvolvimento de uma economia nacional híbrida, que por ser essencialmente periférica e dependente, promove a coexistência e combinação do moderno com o arcaico, ou "uma descolonização mínima, com uma modernização máxima" (p. 209).

Não se formou aqui, portanto, uma burguesia portadora de uma consciência revolucionária, plenamente integrada e consciente de seu destino histórico; mas um estrato social que pretendia uma evolução com a aristocracia agrária, não contra ela, nos moldes de uma revolução "dentro da ordem". As elites beneficiadas pelo sistema escravocrata e senhorial reuniam seus esforços para preservar os aparatos de poder e dominação conquistados na antiga ordem, de modo que o "espírito burguês" foi absorvido parcialmente. Sendo assim,

[...] a falta de elasticidade da ordem social escravocrata e senhorial, por paradoxal que pareça, engolfou a geração da Independência (e as outras subsequentes) na construção das próprias bases do capitalismo dependente 
e do beco sem saída que ele representava para o Brasil. Não houve uma passagem do padrão colonial de crescimento econômico para o padrão de desenvolvimento capitalista. Mas uma rotação do crescimento colonial para o neocolonial e, em seguida (e isso com muita rapidez), para o padrão capitalista de crescimento econômico dependente e de subdesenvolvimento (FERNANDES, 2005, p. 213).

No Brasil, a ascensão das relações de produção capitalistas não poderia conduzir a uma revolução nacional e democrática, uma vez que isso representaria a eliminação da base de poder das elites agrárias e oligárquicas. Nesses termos, a burguesia emergente assume, necessariamente, uma natureza "ultraconservadora e reacionária" (p. 250).

Diante do exposto, pode-se afirmar que a revolução burguesa no Brasil não seguiu uma via clássica na qual a burguesia se alia ao proletariado para pôr fim ao Antigo Regime. Ao contrário, a burguesia se aliou aos setores dominantes da sociedade, consolidando uma revolução "dentro da ordem" e "a partir de cima" (p. 244). Em virtude deste fato, a revolução burguesa no Brasil não realizou suas tarefas democráticas e nacionais, mas cumpriu a função de legitimar o desenvolvimento do capitalismo interno. De acordo com Fernandes, a democracia burguesa torna-se uma "democracia restrita, aberta e funcional só para os que têm acesso à dominação burguesa" (p. 249).

Os setores que têm acesso à dominação burguesa, por sua vez, são uma minoria de privilegiados. Como nos recorda o autor, "certas burguesias não podem ser instrumentais, ao mesmo tempo, para 'a transformação capitalista' e a 'revolução nacional e democrática'” (p. 251). Assim, a revolução burguesa assumirá o caráter de uma "contrarrevolução preventiva" no sentido de antecipar as revoltas do proletariado e legitimar a ordem burguesa. O Estado adquirirá uma forma autocrática ou uma "ditadura de classe preventiva" (p. 368).

A partir de então, a burguesia ganhava condições vantajosas para estabelecer uma associação mais íntima com o capitalismo financeiro internacional; para reprimir, pela violência ou pela intimidação, qualquer ameaça à ordem ou mesmo uma revolução democrático-burguesa e para 
transformar o Estado em instrumento exclusivo do poder burguês, tanto no plano econômico quanto nos planos social e político.

Nesse sentido, conclui Fernandes:

Um capítulo na história econômica do Brasil se encerrou; e, com ele, foi arquivado o ideal de uma revolução nacional democrático-burguesa. Outro capítulo se abriu, pelo qual o passado se repete no presente: mais uma vez, o privilegiamento do agente econômico, social e político principal serve de base a toda uma nova evolução. Só que, agora, aceita a ideia e a prática da revolução de cima para baixo (que é como se 'legitima' a revolução institucional), o sentido da dominação burguesa se desmascara, deixando a nu sua natureza incoercivelmente autocrática, 'contra quem' ela se faz e sua incapacidade de realizar os alvos históricos com que se identificara durante todo o período republicano (FERNANDES, 2005, p. 257-58).

A ditadura militar pode ser considerada uma reedição da solução que a burguesia brasileira historicamente deu aos processos de transformação social: "pelo alto", configurando uma espécie de modernização conservadora. Tratou-se de uma contrarrevolução dirigida pelos setores hegemônicos da burguesia nacional associados ao imperialismo estadunidense e pelas Forças Armadas na tentativa de barrar um modelo de desenvolvimento nacional e democrático.

\section{0 desenvolvimento do capitalismo e a consolidação da revolução burguesa}

De acordo com Fernandes, o capitalismo não possui um único padrão de desenvolvimento, de caráter universal e invariável, mas podem existir diversos modelos de desenvolvimento capitalista, que correspondem às várias formas que o capital assume ao longo da história. Por isso, o autor delimita três fases que marcam a evolução interna do capitalismo no Brasil: a fase de eclosão de um mercado capitalista especificamente moderno; a fase de formação e expansão do capitalismo competitivo e a fase de irrupção do capitalismo monopolista.

Nenhuma dessas fases, no entanto, corresponderia a uma réplica do desenvolvimento capitalista característico das nações centrais e hegemônicas, mas apresentam os traços típicos das nações periféricas e heteronômicas. Além disso, em nenhuma dessas três fases o desenvolvimento capitalista chegou a impor uma ruptura com a 
dependência ao exterior, a desagregação completa do antigo regime ou a superação do subdesenvolvimento e da subordinação ao imperialismo.

A fase de eclosão do mercado capitalista moderno vai da abertura dos portos até meados de 1860. Essa fase é caracterizada por um enlace da economia interna com o mercado mundial, que "exportava desenvolvimento econômico capitalista" (p. 264). Através deste mercado, as parcelas do excedente econômico, retidas dentro do país, iriam encontrar formas de aplicação reprodutiva fora do circuito escravista, dinamizando a acumulação estamental em um padrão neocolonial de desenvolvimento. Este padrão de desenvolvimento, no entanto, gerou apenas um leve impulso nas relações de intercâmbio com o mercado mundial e uma gradual aceleração do crescimento urbano-comercial, mantendo o sistema de produção escravista.

A segunda fase, denominada formação e expansão do capitalismo competitivo, tem seu início aproximadamente em 1860 e perdura até meados da década de 1950. É o período em que o sistema econômico se diferencia, criando as bases para a industrialização no setor urbanocomercial, em um primeiro momento, e estendendo-se gradativamente ao setor arcaico. 0 autor destaca que tal desenvolvimento foi induzido de fora, de forma limitada, pois "o que entrava em jogo não era o desenvolvimento capitalista em si mesmo, mas a adaptação de certas transformações da economia brasileira aos dinamismos em expansão das economias centrais" (p. 277).

Esse dinamismo do mercado foi crucial na consolidação dos estímulos para a constituição interna de um sistema de produção propriamente capitalista. 0 mercado irrompe como uma força revolucionária, que desagrega completamente a ordem escravista preexistente, engendrando uma nova formação societária fundada em relações competitivas.

Na segunda metade do século XIX, "o lastro interno não era suficiente para amparar todo o complexo processo de consolidação, irradiação e disseminação do mercado capitalista moderno" (p. 270). A urbanização ocorria de forma lenta, uma vez que o centro da vida econômica era a 
produção do café e o trabalho escravo ainda predominava sobre a contratação de força de trabalho livre. Entretanto, as pressões externas do mercado mundial e as pressões internas da dinâmica do crescimento econômico forçavam o país a adaptar-se aos requisitos do padrão de desenvolvimento inerente ao capitalismo comercial.

As grandes potências imperialistas que disputavam a "partilha do mundo" voltavam seus olhos para as reservas de recursos e para o enorme potencial produtivo de um país continental como o Brasil e, por isso, se dispuseram a intervir ativamente na reorganização institucional do espaço econômico interno. Conforme Fernandes:

De um lado, o desenvolvimento induzido de fora acelerava a revolução econômica no setor novo, porém em termos de requisitos limitados, pois o que entrava em jogo não era o desenvolvimento capitalista em si mesmo, mas a adaptação de certas transformações da economia brasileira aos dinamismos em expansão das economias centrais. Ou seja, o desenvolvimento induzido somente selecionava e transferia dinamismos que aceleravam transformações capitalistas mais ou menos necessárias ao processo de incorporação em curso; eles eram insuficientes ou neutros para transformações capitalistas mais complexas e, de qualquer modo, não poderiam gerar, por si mesmos, um desenvolvimento capitalista autônomo e autossustentado, análogo ao das economias centrais e hegemônicas (FERNANDES, 2005, p. 277).

O impulso externo provocado pelas economias centrais contribuía, ao mesmo tempo, para dinamizar o desenvolvimento econômico e aprisionar o país na condição de dependência, ao impedir a formação de um padrão autônomo de crescimento econômico.

A consolidação do mercado capitalista, ao exercer pressões sobre a diferenciação e reintegração do sistema econômico, promove um surto industrial. 0 ciclo de expansão das indústrias perdura do final do século XIX até a crise de 1929, período em que ocorre a substituição da produção artesanal pelas manufaturas.

Já a fase de irrupção do capitalismo monopolista, que se acentua na década de 1950 e se consolida com o golpe de 1964, é marcada pela abertura do país às grandes corporações e suas operações comerciais, financeiras e industriais. Conforme Fernandes, a implantação e consolidação desse padrão de desenvolvimento nas economias periféricas 
assumem um caráter especificamente político, devido à ascensão do "socialismo num só país" e o emergente "perigo comunista". Fazia-se necessário, nesse período, consolidar o domínio capitalista nas nações periféricas frente à ameaça socialista.

A economia brasileira se relacionou com a expansão do capitalismo monopolista segundo a forma típica que este assumiu com referência à periferia. As grandes corporações não se empenharam em irradiar o capitalismo monopolista a partir de dentro do país. Ao contrário, "as matérias-primas e as parcelas do excedente econômico drenadas para fora se polarizam na expansão do capitalismo monopolista nas próprias economias centrais" (p. 299).

Os requisitos do novo padrão de desenvolvimento capitalista exigiam um elevado grau de estabilidade política que só uma extrema concentração do poder seria capaz de garantir:

[...] nos momentos mais críticos da transição, que ainda não foram vencidos, operou-se uma dissociação acentuada entre desenvolvimento econômico e desenvolvimento político. Isso fez com que a restauração da dominação burguesa levasse, de um lado, a um padrão capitalista altamente racional e modernizador de desenvolvimento econômico; e, concomitantemente, servisse de pião a medidas políticas, militares e policiais, contrarrevolucionárias, que atrelaram o Estado nacional não à clássica democracia burguesa, mas a uma versão tecnocrática da democracia restrita, a qual se poderia qualificar, com precisão terminológica, como uma autocracia burguesa (FERNANDES, 2005, p. 312-13, grifos nossos).

Para Fernandes, um dos principais traços da revolução burguesa no Brasil é "uma forte dissociação pragmática entre desenvolvimento capitalista e democracia" (p. 340). Por isso, a revolução burguesa na periferia é um fenômeno essencialmente político, voltado para a "criação, consolidação e preservação de estruturas de poder predominantemente políticas, submetidas ao controle da burguesia ou por ela controláveis em quaisquer circunstâncias" (p. 343). Prossegue o autor:

Não estamos na era das 'burguesias conquistadoras'. Tanto as burguesias nacionais da periferia quanto as burguesias das nações capitalistas centrais e hegemônicas possuem interesses e orientações que vão noutra direção. Elas querem: manter a ordem, salvar e fortalecer o capitalismo, impedir que a dominação burguesa e o controle burguês sobre o Estado nacional se deteriorem (FLORESTAN FERNANDES, 2005, p. 343). 
0 autor suscita, nesse momento da análise, uma indagação determinante: mesmo tornando-se autocrático, pode o poder burguês suprimir as bases econômicas e os fundamentos políticos da dominação burguesa, sem destruir-se? A resposta apresenta-se na sequência: "Ora, enquanto existir capitalismo haverá classes sociais e os mecanismos básicos de relações de classes terão de passar por processos de acomodação, competição e conflito das classes entre si” (p. 323).

A alteração do padrão de desenvolvimento no Brasil operou transformações na base econômica e, portanto, na organização das classes sociais. Como demonstra Fernandes, apesar de encoberto e reprimido, o conflito não deixa de existir e de estar presente nas estruturas e nas relações das classes. As mudanças impostas pelo capitalismo monopolista ampliaram e aprofundaram as desigualdades econômicas, sociais e políticas, contribuindo para o fortalecimento da consciência de classe. 0 proletariado, nesse sentido, adquire um novo peso econômico, social e político na sociedade brasileira.

Esse quadro fortalecerá o sindicalismo e as organizações operárias que, pela primeira vez na história do capitalismo no Brasil, deixarão de ser "meros instrumentos e vítimas-mudas passivas do desenvolvimento capitalista" (p. 328), passando, agora, a exercer pressões para que o capitalismo também se adapte às suas necessidades. Nas palavras do sociólogo paulista:

A importância do aparecimento de um novo tipo de operário é óbvia. Ele acarretará a renovação (para dizer o menos) do movimento sindical e, em um plano mais amplo e profundo, levará a sociedade brasileira, finalmente, a conhecer qual é a natureza e o sentido das pressões econômicas, sociais e políticas das classes operárias, quando estas se configuram como uma 'força social' da história (FLORESTAN FERNANDES, 2005, p. 330).

A burguesia brasileira que sempre esteve acostumada a voltar as costas aos interesses e às pressões da classe trabalhadora, agora terá de agir com mais cautela e menos arbitrariedade na condução do país. 0 panorama descrito abre margem para a coexistência de revoluções antagônicas: "uma, que vem do passado e chega a termo sem maiores perspectivas. Outra, que lança raízes diretamente sobre 'a construção do 
futuro no presente'” (p. 344). A burguesia, portanto, não terá de lutar somente para manter suas vantagens e privilégios de classe, mas, sobretudo, para garantir sua sobrevivência e a sobrevivência do capitalismo.

A "autocracia burguesa" só terá condições de se manter numa condição transitória. Portanto, o Estado autocrático precisará forjar outras estratégias para manter sua legitimação sobre os "de baixo", compondo o que Fernandes designou como "democracia de cooptação" (p. 416). Neste quadro, o Estado burguês buscará prevenir as revoltas populares por meio do apassivamento e controle da classe trabalhadora, promovendo ações minimalistas no sentido da garantia de direitos e concedendo algumas conquistas progressistas para que o metabolismo da acumulação capitalista permaneça inalterado.

De acordo com o autor, a fragilidade de tal estratégia se assenta no fato de que as classes burguesas mais conservadoras e reacionárias considerarão exagerado o preço que terão de pagar à sobrevivência do capitalismo dependente via democracia de cooptação, apesar de ser a única possibilidade de abertura democrática a ser posta em prática. Ao passo que a democracia de cooptação teria pouca eficácia em uma nação com tamanha desigualdade social e extrema concentração de riqueza, o que poderia conduzir ao efeito inverso de sua intencionalidade essencial, ocasionando um acirramento dos conflitos de classe. Nesse sentido, Florestan conclui sua obra magistral apontando as duas possibilidades que estavam em aberto: a consolidação do capitalismo monopolista ou a eclosão do socialismo.

\section{Considerações finais}

O caráter do Estado no Brasil e sua relação com as classes sociais expressam características estruturais derivadas da forma do capitalismo dependente que aqui se desenvolveu. A formação social do Brasil carrega as marcas impressas pela herança colonial e seus desdobramentos sobre a inserção subalterna do Brasil na ordem global. A revolução burguesa brasileira foi conduzida pelo alto, por intermédio de uma aliança, ao nível 
do Estado, entre os setores dominantes e sem uma efetiva participação dos "de baixo" nesse processo. Os sujeitos dessa revolução burguesa no Brasil eram desprovidos de uma orientação democrática e nacional e, por isso, não tinham como meta a construção de um desenvolvimento capitalista interno autônomo. Em virtude disso, o legado da transição ao capitalismo foi um grande déficit nos marcos civilizatórios e políticos conquistados pelas clássicas revoluções democrático-burguesas.

Os processos de transformação social no Brasil são repletos de "modernização conservadora" e revoluções "pelo alto", elementos típicos das vias "não-clássicas" de desenvolvimento do capitalismo. Não houve uma ruptura definitiva com o estatuto colonial para a instauração do modo capitalista de produção - requisito primordial em outras formações -, e as estruturas agrárias foram conservadas e adaptadas à dinâmica industrial, que delas se abasteceu em seu desenvolvimento. Da mesma forma, a existência de uma periferia que vive à margem dos ganhos do avanço econômico e social é um elemento central para a imposição de mecanismos como a superexploração da força de trabalho, na medida em que contribui para rebaixar o padrão de vida da população.

Com base no estudo dessas valiosas contribuições, pode-se depreender que a revolução burguesa no Brasil e a modernidade capitalista se completam conservando os traços da condição periférica e dependente: a conciliação do moderno com o arcaico; a apropriação do Estado por parte das elites e a canalização de seus aparatos para o atendimento de interesses privados em detrimento do público, bem como uma forte dissociação entre capitalismo e democracia. A reversão destas linhas de força da nossa formação social não pode se dar senão pela ruptura com o próprio capitalismo.

\section{Referências:}

FERNANDES, Florestan. A revolução burguesa no Brasil: ensaio de interpretação sociológica. 5. ed. São Paulo: Globo, 2005. 